Article

\title{
Innovative Recycling of Lime Slaker Grits from Paper-Pulp Industry Reused as Aggregate in Ambient Cured Biomass Fly Ash-Based Geopolymers for Sustainable Construction Material
}

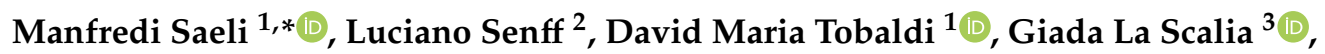 \\ Maria Paula Seabra ${ }^{1}$ and João Antonio Labrincha ${ }^{1}$ \\ 1 Department of Materials and Ceramics Engineering, Aveiro Institute of Materials, University of Aveiro, \\ Campus Universitário de Santiago, 3810-193 Aveiro, Portugal; david.tobaldi@ua.pt (D.M.T.); \\ pseabra@ua.pt (M.P.S.); jal@ua.pt (J.A.L.) \\ 2 Department of Mobility Engineering, Federal University of Santa Catarina, 89218-000 Joinville, Brazil; \\ lsenff@gmail.com \\ 3 Department of Engineering, University of Palermo, Viale delle Scienze, Bld 8, 90128 Palermo, Italy; \\ giada.lascalia@unipa.it \\ * Correspondence: manfredi.saeli@ua.pt
}

Received: 7 May 2019; Accepted: 21 June 2019; Published: 25 June 2019

\begin{abstract}
Lime slaker grits and biomass fly ash are solid wastes produced by the Kraft paper-pulp industry that are commonly disposed of in landfill. However, recent studies and European regulations discourage such disposal practices. This work investigates an alternative and innovative way to recycle and reuse these wastes in the production of green geopolymeric mortars intended for application in the construction industry. Here, biomass fly ash was used as the main source of alumino-silicate in the binder precursor (70 wt.\% substitution to metakaolin), and grits (ranging from 1-12.5 mm, as provided by the industry) were reused as aggregate. Aggregate granulometry was also completed by using a commercial natural siliceous sand $(<1 \mathrm{~mm})$. Mortars using sand only were prepared for comparative reasons. The implemented mix was designed to investigate the influence of the grits on the mortar's properties such as its binder/aggregate ratio, workability, bulk density, water sorptivity, and compressive strength. At the same time, waste reuse was analysed in light of its limitations and potentialities. Moreover, in the pursuit of sustainability, the manufacturing process that was followed was highly cost-effective in ambient curing conditions $\left(20^{\circ} \mathrm{C}, 65 \% \mathrm{RH}\right)$, which avoided the use of any external source of energy as commonly used in geopolymers processing. The achieved results proved that the combined use of these wastes, which to date has hardly been explored, along with ambient manufacturing conditions increases the material sustainability. The produced mortars are suitable for innovative applications in various fields, with a particular focus on construction and contribute to the circular economy.
\end{abstract}

Keywords: construction; geopolymer concrete; biomass fly ash; lime slaker grits; recycling; paper-pulp industry

\section{Introduction}

Worldwide, the intense industrial activity generates enormous quantities of waste every year-the treatment and disposal of this waste poses several difficulties and concerns. Therefore, waste management has become a highly cost-effective way to transform, valorise, and reuse these by-products, especially from the perspective of improving the circular economy [1,2]. 
Nowadays construction is recognised as highly unsustainable because of its use of massive amounts of non-renewable raw materials and energy consumption. Moreover, it generates enormous volumes of greenhouse gas and waste [3-5]. In this scenario, cement manufacture is particularly critical, as it is comprised of several associated materials (i.e., aggregates). It is estimated that for every produced ton of Ordinary Portland Cement (OPC), around 0.7-1.1 ton of $\mathrm{CO}_{2}$ is generated [6,7]. Nevertheless, cement use is unavoidable due to the unequivocal need for new structures and infrastructures [8]. Hence, there is an extraordinary need to develop alternative materials and cost-effective manufacturing processes that can reduce the unsustainability associated with construction.

Geopolymers (GP) are considered a valid and sustainable alternative to OPC as they show properties suitable for diverse applications in construction [9-11] such as a fast setting time, low volumetric shrinkage, outstanding mechanical performance, and high resistance to chemicals and ageing [10-15]. Additionally, GP manufacture is highly cost-effective and simple, and is claimed to generate lower $\mathrm{CO}_{2}$ emissions than OPC [16,17]. GP are inorganic alkali-activated binders made with a reactive solid alumina-silicate source, commonly metakaolin (MK), that interacts with an alkaline solution $[18,19]$ to form a stable gel $[20,21]$.

This study investigates the valorisation and reuse of two wastes generated in a local Kraft pulp industry [22-24], namely, biomass fly ash (BFA) and lime slaker grits (grits), to prepare novel GP-mortars intended for applications in the construction industry. Very often these, and other industrial wastes are disposed of in landfill without considering the potential embedded polluting agents. As a consequence, recent European regulation [25] discourages such disposal practices due to the serious risk of soil and water contamination and the consequent environmental degradation. According to recent knowledge and guidelines, this work investigates an alternative and innovative way to recycle and reuse the aforementioned wastes.

The used BFA is produced in the biomass boiler employed for energy production at mill sites and is collected at the electrostatic precipitator as waste. BFA has occasionally been investigated in concrete applications [26-28] and its analogous use in GP is fairly recent [25-29]. In these previous works, BFA was reused as an alternative source of aluminium and silicon to partially replace the MK in the manufacture of GP-binder [30-35].

Grits are a granular alkali waste and derive from the clarification of molten inorganic salts by a lime slaker during the recovery of the chemical liquor used as a wood digester. Grits are mainly comprised of calcite, making them suitable for reuse, especially in construction. Nevertheless, their recycling potential has rarely been investigated [36-38], and to date, their use in GP materials is fairly unknown.

The manufacturing process followed in this study is highly cost-effective in ambient curing conditions $\left(20^{\circ} \mathrm{C}, 65 \% \mathrm{RH}\right)$, and thus avoids any external source of energy, which is common practice in GP processing. Additionally, it involves simple, reproducible, and low-cost procedures that contribute to reducing the process footprint.

The novel GP-mortars were investigated to evaluate the best design mix to optimise waste incorporation and mechanical performance according to various binder to aggregate ratios. Also, different aggregate mixes were tested. To date, this is the first time that the (joint) use of these two wastes (BFA and grits) as raw materials has been reported in geopolymer technology, especially for applications in construction. Valorisation and reuse of industrial waste is a compelling business, with great repercussions in the area of construction, and as the huge amount of waste that is generated yearly has become environmentally and financially unsustainable. Furthermore, a novel low-cost and effective way to treat and dispose of wastes is analysed to make GP-technology a part of an overall "Green Concrete" industry in accordance to the most recent international codes of practice. 


\section{Material and Methods}

\subsection{Materials}

In this study, the GP-binder was designed $\left(\mathrm{SiO}_{2} / \mathrm{Al}_{2} \mathrm{O}_{3}=5.27, \mathrm{Na}_{2} \mathrm{O} / \mathrm{Al}_{2} \mathrm{O}_{3}=1.31, \mathrm{Na}_{2} \mathrm{O} / \mathrm{SiO}_{2}\right.$ $=0.25$, and $\left.\mathrm{H}_{2} \mathrm{O} / \mathrm{Na}_{2} \mathrm{O}=15.9\right)$ and manufactured according to previous studies $[39,40]$. The used formulation uses a mixture of BFA (70 wt.\%) and MK (30 wt.\%) as a solid source of alumina and silica.

BFA presents $\alpha$-quartz, calcite, mica group mineral (mixture of muscovite/illite), and microcline as crystalline phases. Benchmark MK was purchased as Argical ${ }^{\mathrm{TM}}$ by Univar ${ }^{\circledR}$ and used to adjust the GP desired molar oxide ratios. The sum of $\mathrm{SiO}_{2}$ and $\mathrm{Al}_{2} \mathrm{O}_{3}$ is $53.3 \mathrm{wt} . \%$ for $\mathrm{BFA}$ and $98.7 \mathrm{wt} . \%$ for MK. The alkaline activation was achieved by using a solution of sodium silicate $\left(\mathrm{H}_{2} \mathrm{O}=62.1 \mathrm{wt} . \%\right.$; $\mathrm{SiO}_{2} / \mathrm{Na}_{2} \mathrm{O}=3.15$; Quimialmel, D40-PQ) and sodium hydroxide (ACS reagent, 97\%; Honeywell). The $\mathrm{NaOH}$ solution $(10 \mathrm{M})$ was prepared by dissolving sodium hydroxide pellets in distilled water at least $24 \mathrm{~h}$ prior to use. The used molarity was selected based on the cited previous works.

Grits have a particle size distribution ranging between $1-12.5 \mathrm{~mm}$, with a minor $(<2 \mathrm{wt} . \%)$ dust fraction $(<1 \mathrm{~mm})$, and were used as aggregate. Prior to use, grits were dried at $60{ }^{\circ} \mathrm{C} / 24 \mathrm{~h}$ in a conventional oven to remove the moisture ( $\sim \mathrm{wt} . \%$ at the mill site). The manufacture process could be implemented if grits were naturally dried at the mill site. That would reduce the overall energy employed for a greener material and manufacture. Commercial natural siliceous sand, provided by Saint-Gobain Weber Portugal, was used as fine aggregate.

BFA and grits do not contain expressive amounts of organic components or unstable/hazardous elements (see Section 3.1. Waste Characterisation). Thus, their use in construction applications is potentially feasible.

\subsection{Processing Details}

GP-mortar specimens were prepared according to EN 998-2:2016, adapting the common procedure for traditional cement-based mortars. Mortar manufacture consisted of: (a) dry hand mixing for $1 \mathrm{~min}$ to ensure a uniform blend of MK and BFA; (b) homogenisation of sodium hydroxide and silicate at $50 \mathrm{rpm}$ for $5 \mathrm{~min}$; (c) mixture of the alkaline solution with the solid precursors at $60 \mathrm{rpm}$ for $9 \mathrm{~min}$; (d) adding the aggregate and mixing for $1 \mathrm{~min}$ at the same speed to ensure homogeneity; (e) pouring the fresh slurry into standard metallic moulds (standard dimensions of $40 \times 40 \times 160 \mathrm{~mm}$ ) and vibrating for $2 \mathrm{~min}$ on a vibrating table to achieve compactness and remove any entrained air; (f) sealing the moulds with a plastic film and letting the specimens harden for $24 \mathrm{~h}$ in ambient conditions $\left(20^{\circ} \mathrm{C}\right.$, $65 \% \mathrm{RH})$, and (g) unsealing and demoulding the hardened samples, and curing at ambient conditions until testing.

This procedure was initially tested in [41].

\subsection{Characterisation of the Materials}

The mineralogical composition of the wastes was evaluated by X-ray diffraction (XRD) using a Cu $\mathrm{K} \alpha$ radiation, $5-80^{\circ} 2 \theta, 0.02^{\circ} 2 \theta$ step-scan and $10 \mathrm{~s} /$ step). The chemical composition was evaluated by X-ray fluorescence (XRF) using a Panalytical Axios spectrometer according to ASTM E1621-13. Loss on ignition (LOI) at $1000^{\circ} \mathrm{C}$ was also determined by measuring the weight change of the dried sample-volatile materials-after ignition $\left(1000{ }^{\circ} \mathrm{C}, 15 \mathrm{~min}\right.$ dwell). BFA particle size distribution was determined by laser diffraction (Coulter LS230 analyser, Fraunhofer method and Polarisation Intensity Differential Scattering), and the specific surface area (according to Brunauer-Emmett-Teller-BET method) was also measured. Grits and sand particle size distribution was determined according to EN 933-2:1995. The morphology and microstructure were investigated by optical microscopy using a Nikon SMZ18 and by scanning electron microscopy (SEM) using a Hitachi analytical FE-SEM SU-70, respectively.

The consistency (spread) of the fresh GP-mortars was estimated by flow table testing according to EN 1015-3:1999. Bulk density was calculated as the average of three specimens. The setting time (initial 
and final) was estimated by the Vicat test according to EN 196-3:2016. The percentage of the cross area occupied by the aggregates was calculated as a parameter of the inert segregation tendency. The water absorption was determined by the Archimedes principle (weight variation, $\Delta \mathrm{P} / \mathrm{P} \%$ ); the capillary coefficient according to EN 1015-18. Three replicas were used to calculate the mean values for both of the sorptivity tests. The mechanical performance was determined according to EN 1015-11 and EN 998-2 by means of the uniaxial compressive strength (UCS) test. A universal testing machine (Shimadzu, AG-25TA), provided with a $250 \mathrm{kN}$ load cell, running at $0.5 \mathrm{~mm} / \mathrm{min}$ displacement rate, was used. The software that returned the measured load and strain values was Trapezium v. 1.2.4. The mean values were obtained from three tests randomly taken from the sample batch. Values of axial strain $(\varepsilon)$ were also calculated as the change $\%$ in specimens' height $(\Delta \mathrm{L} / \mathrm{L})$.

\subsection{Tested Formulations}

The mix design was formulated to investigate the possibility of producing a uniform material, maximising the incorporation of the grits and improving the mechanical performance. Engineering properties, i.e., paste workability and compressive strength, were evaluated in relation to possible applications in construction, according to the relevant international standards and guidelines (i.e., EN 998-2, ACI 116R-00, Eurocode 2, Italian D.M. 17/01/2018). Therefore, the acceptable minimum UCS value was $10 \mathrm{MPa}$ (at 28 days of curing) in order to classify these novel materials in resistance class "M10". This is an essential requirement for mortars intended for structural applications. Nevertheless, other applications were not excluded (i.e., lightweight concretes, environmental uses, etc.).

The used GP-binder formulation, previously optimised in [39,40], predicted a solid part comprising $70 \mathrm{wt.} \% \mathrm{BFA}$ and $30 \mathrm{wt} . \% \mathrm{MK}$ as alumino-silicate source; the alkaline activator is granted by a mixture of sodium hydroxide and sodium silicate (ratio 1:3). Binder liquid/solid ratio (L/S) resulted 0.78. The main characteristics of this binder follow: bulk density $-1307 \mathrm{Kg} / \mathrm{m}^{3}$; sorptivity by immersion- $38 \%$; coefficient of capillarity- $0.87 \mathrm{~kg} /\left(\mathrm{m}^{2} \cdot \mathrm{min}^{0.5}\right)$; compressive UCS-22.15 $\pm 1.22 \mathrm{MPa}$.

The tested GP-mortar formulations are shown in Table 1. The aggregate was used in five proportions - that is, a binder/aggregate ratio (B/A) — to evaluate its influence on the GP-mortars' engineering properties. Three different GP-mortar families were designed: (I) with sand only as aggregate; (II) using a mixture (50/50 wt.\%) of sand and grits as aggregate; and (III) using grits only as aggregate. According to previous studies, the characteristics of mortars (I) are reported for comparative reasons and to evaluate the performance of the grits-based materials. Mortars of family (II) are designed to broaden the aggregate particle size distribution, lower the phenomenon of segregation, and obtain a more homogeneous and better performing material. Mortars of family (III) are designed to assess the possibility of exploiting the grits only as novel aggregate, avoiding further depletion of natural resources and considerably improving the material sustainability.

Table 1. Experimental plan for the tested GP-mortars.

\begin{tabular}{ccccc}
\hline Mortar Family & Specimen N. & B/A Ratio & Aggregate Nature & L/S Ratio \\
\hline & 1 & $1: 1$ & & 0.391 \\
(I) & 2 & $1: 2$ & & 0.261 \\
& 3 & $1: 3$ & sand & 0.196 \\
& 4 & $1: 4$ & & 0.156 \\
& 5 & $1: 5$ & & 0.130 \\
\hline & 6 & $1: 1$ & & 0.391 \\
(II) & 7 & $1: 2$ & & 0.261 \\
& 8 & $1: 3$ & sand + grits & 0.196 \\
& 9 & $1: 4$ & & 0.156 \\
& 10 & $1: 5$ & & 0.130 \\
\hline & 11 & $1: 1$ & & 0.391 \\
(III) & 12 & $1: 2$ & & 0.261 \\
& 13 & $1: 3$ & grits & 0.196 \\
& 14 & $1: 4$ & & 0.156 \\
& 15 & $1: 5$ & & 0.130 \\
\hline
\end{tabular}




\section{Results and Discussion}

\subsection{Waste Characterisation}

The mineralogical composition of the BFA and grits is presented in Figure 1; their chemical compositions are presented in Table 2. The XRD pattern of BFA reveals $\alpha$-quartz, calcite, mica group of minerals (like a mixture of muscovite/illite, the latter would justify the presence of iron detected via $\mathrm{XRF}$ ), and microcline as the crystalline phases detected. However, minor amounts of amorphous phase cannot be excluded [34]. In accordance, XRF shows that the sum of $\mathrm{SiO}_{2}$ and $\mathrm{Al}_{2} \mathrm{O}_{3}$ is only $53.3 \mathrm{wt}$.\%. The BFA particle size distribution ranges between 3.7-105.3 $\mu \mathrm{m}$, with a mean value of $49.3 \mu \mathrm{m}$, and its specific surface area (BET) value is $3.05 \mathrm{~m}^{2} / \mathrm{g}$.

The grits XRD pattern reveals that $\mathrm{CaCO}_{3}$ is the main component with minor amounts of $\mathrm{NaHCO}_{3}$. Both the XRD analyses are in accordance with the XRFs. Grits present a particle size distribution ranging between $1-12.5 \mathrm{~mm}$, with a minor ( $<2 \mathrm{wt} . \%)$ dust fraction $(<1 \mathrm{~mm})$, as furnished by the industry. It is presented in Figure 2 along with that of sand. Grit grains are round and smooth (Figure 3A,B) and their morphology appears dense, compact, and made of cemented structures (Figure 3C,D). Particles are assembled in branched thin plate-like shapes with an average size of $5 \mu \mathrm{m}$. Finally, grits show an apparent density of $1522 \mathrm{~kg} / \mathrm{m}^{3}$ and a quite low water absorption value, calculated as $1.5 \%$, due to the highly compact nature of the waste matrix.

The used sand is a standard natural siliceous material, used in the formulation of commercial mortars. Its mean particle size is $841 \mu \mathrm{m}$ and the specific surface area is $0.57 \mathrm{~m}^{2} / \mathrm{gr}$.
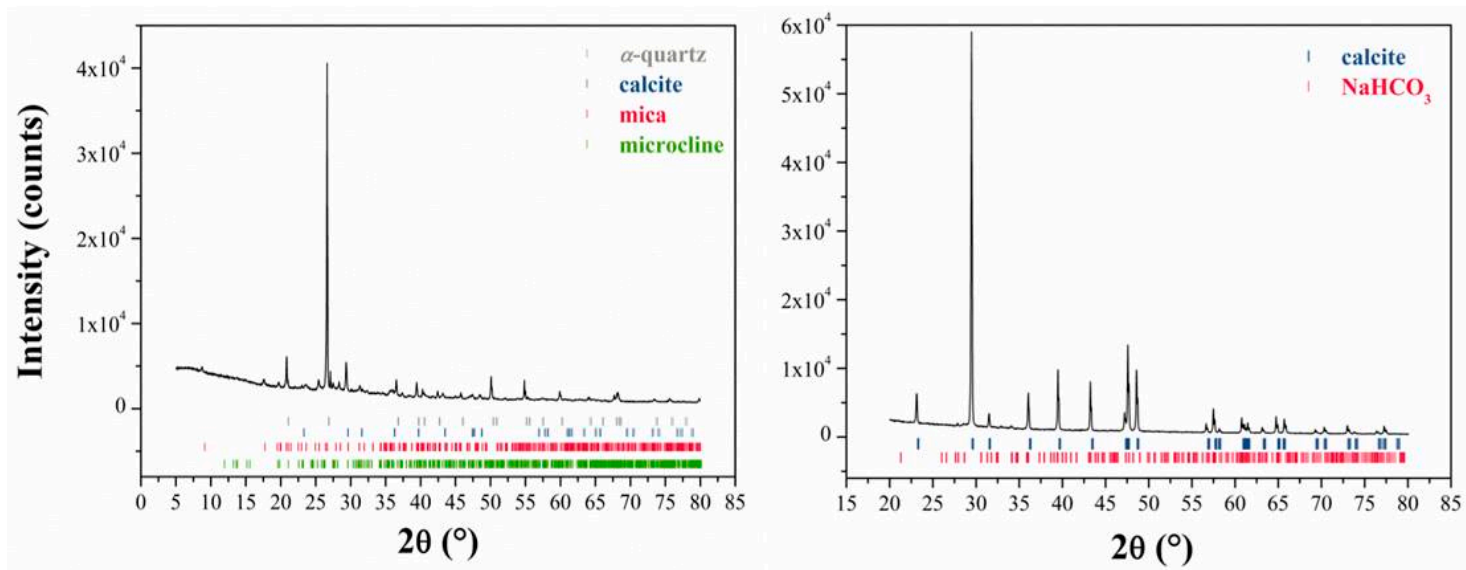

Figure 1. XRD patterns of BFA (left) and grits (right).

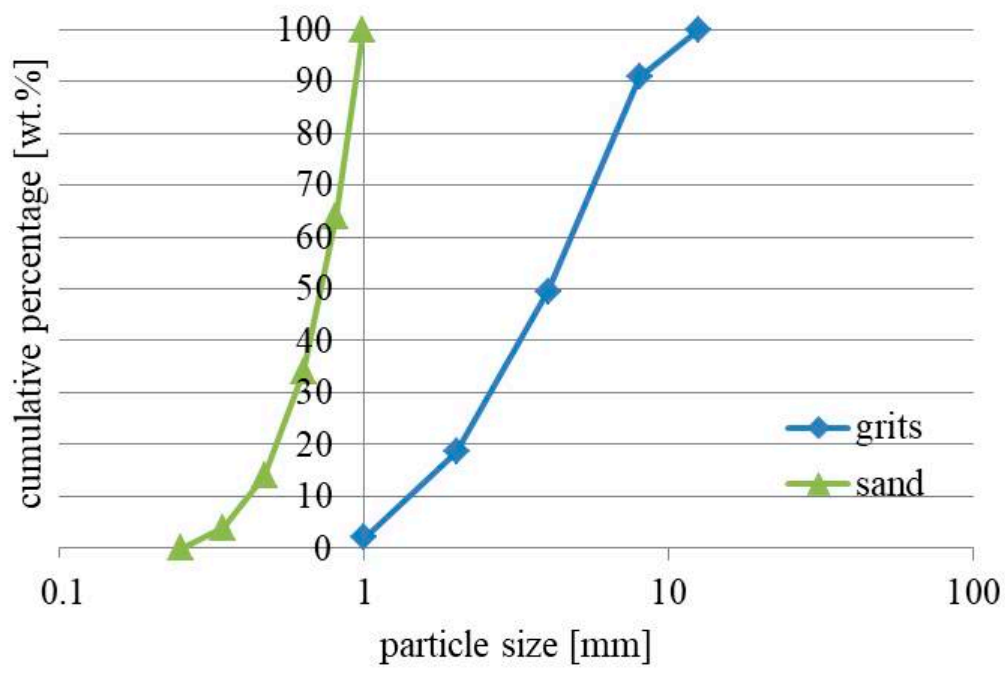

Figure 2. Grits and sand particle size distribution. 

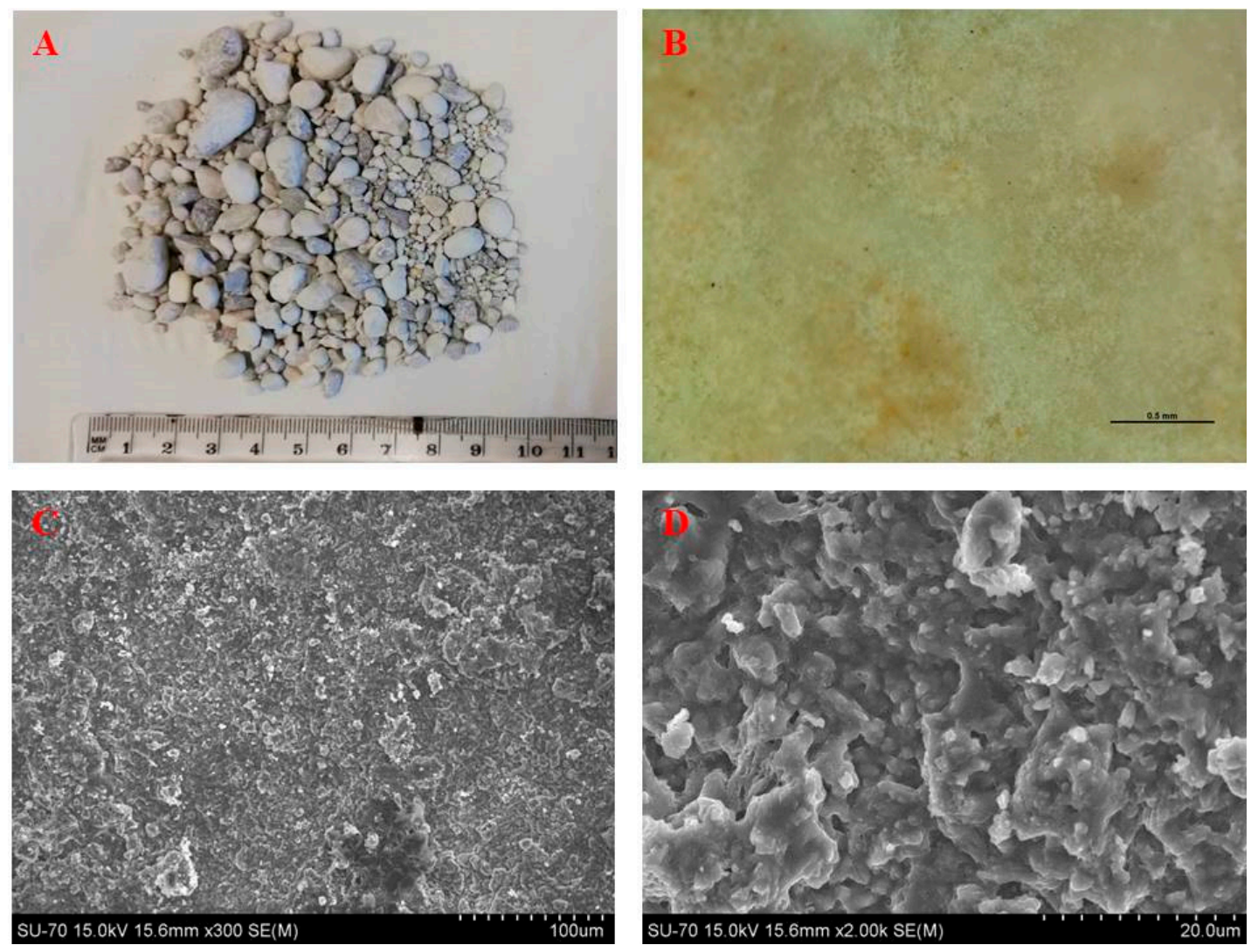

Figure 3. Grits images: (A) photograph; (B) optical microscopy (4X magnifications); (C,D) SEM images (300X and 2000X magnification, respectively).

Table 2. Chemical composition (major oxides) of BFA and grits, as estimated by XRF.

\begin{tabular}{ccc}
\hline Oxides [wt.\%] & BFA & Grits \\
\hline $\mathrm{SiO}_{2}$ & 38.5 & 0.47 \\
$\mathrm{CaO}$ & 16.7 & 49.45 \\
$\mathrm{Al}_{2} \mathrm{O}_{3}$ & 14.8 & 0.29 \\
$\mathrm{~K}_{2} \mathrm{O}$ & 5.97 & 0.27 \\
$\mathrm{Fe}_{2} \mathrm{O}_{3}$ & 5.94 & 0.05 \\
$\mathrm{MgO}$ & 3.44 & 0.45 \\
$\mathrm{SO}_{3}$ & 2.66 & 1.86 \\
$\mathrm{Na}_{2} \mathrm{O}$ & 1.53 & 5.52 \\
$\mathrm{P}_{2} \mathrm{O}_{5}$ & 1.12 & 0.38 \\
$\mathrm{TiO}_{2}$ & 0.76 & - \\
$\mathrm{MnO} \mathrm{O}$ & 0.50 & - \\
$\mathrm{LO}$ & 6.39 & 41.1
\end{tabular}

* The high value is explained by the $\mathrm{CaCO}_{3}$ decomposition in $\mathrm{CaO}+\mathrm{CO}_{2}$ at high temperature.

\subsection{Mortar Characterisation}

\subsubsection{Physical Properties}

The consistency of fresh mortars indicates the ease with which the material can be mixed, placed, and finished to a homogenous and efficient state. A suitable consistency usually depends on the specific application. If consistency is not adequate, then the material might not show the required qualities once set. If the slurry is too pasty (consistency $<15 \mathrm{~cm}$ ) then it might be almost unmouldable or inapplicable, and large voids may form within the paste. This could cause weakness, structural failure, and high water absorption. On the contrary, high fluidity may generate aggregate segregation 
and delay in setting and curing. A consistency ranging between $18-22 \mathrm{~cm}$ guarantees good material workability with suitable compaction and homogeneity [42]. However, consistency can be modified by adding chemicals (i.e., plasticisers), but their use is avoided in this study to prevent any undesired chemical reactions.

Pictures of the flow table tests and spread values of the tested formulations are presented in Figures 4 and 5A, respectively. Figure 5B shows the bulk density of the hardened specimens. As expected, increasing the amount of aggregate reduces the workability. When added in minor amounts (1:1) their effect on the slurry consistency is less evident, with the spread being similar to that of the pure binder. More precisely, for all of the families it resulted $\geq 30 \mathrm{~cm}$. This will also cause segregation of aggregates. On the other hand, the 1:5 formulations show very poor workability. Generally speaking, the mortars using only one type of aggregate, sand or grits, show the lowest and highest workability, respectively. More particularly, family (I) tends to become highly pasty with aggregate due to its small particle size. This requires more water to wet their surface, with a significant reduction in liquid availability. Consequently, the 1:5 formulation resulted in mostly unworkable mortars $(10 \mathrm{~cm}$ spread) with the presence of large voids (which also influence the bulk density). On the contrary, it was observed that the mortar family (III) presents a suitable consistency even for the 1:5 B/A ratio $(\approx 19 \mathrm{~cm})$. This is explainable by the grits' larger particle size, and very low water absorption, which leads to more fluidity. In all cases, the resulting mortars from family III are suitable for construction applications. Finally, the mortars using a mixture of grits and sand exhibit an intermediate behaviour.

As a general trend, increasing the amount of aggregate tends to increase the bulk density of the hardened GP-mortars (Figure 5B). Moreover, because grits are heavier than sand, their use leads to higher densities. Again, when a mixture of sand and grits is used, then intermediate densities are calculated. Furthermore, as discussed, density also depends on the paste workability (a too pasty slurry may generate large voids). This is particularly evident for specimen $n .5$ (family (I), 1:5 B/A, $100 \mathrm{wt.} \%$ sand), which is also visible in Figure 6 (mortar cross sections, top right).

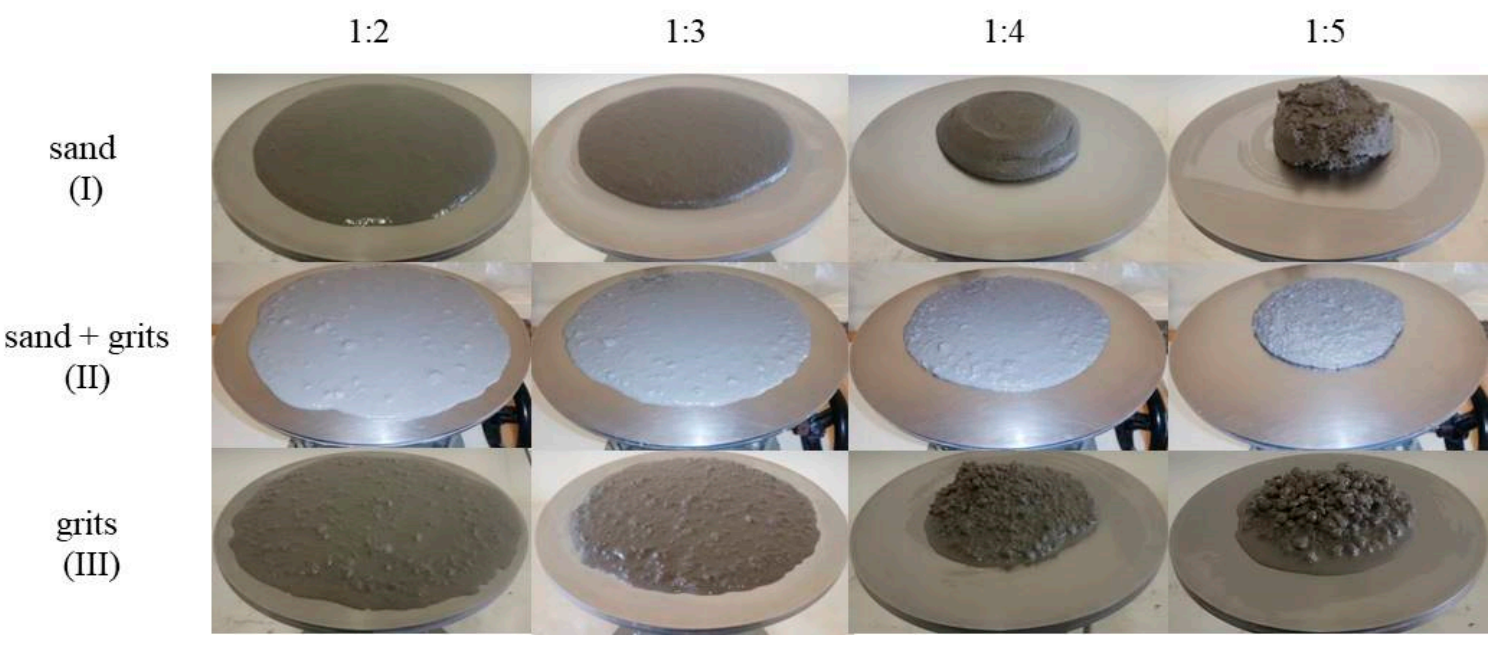

Figure 4. Flow table test photographs. Pictures of the 1:1 B/A are not shown due to the highly liquid nature (spread $>30 \mathrm{~cm}$ ); the material went off the table. 

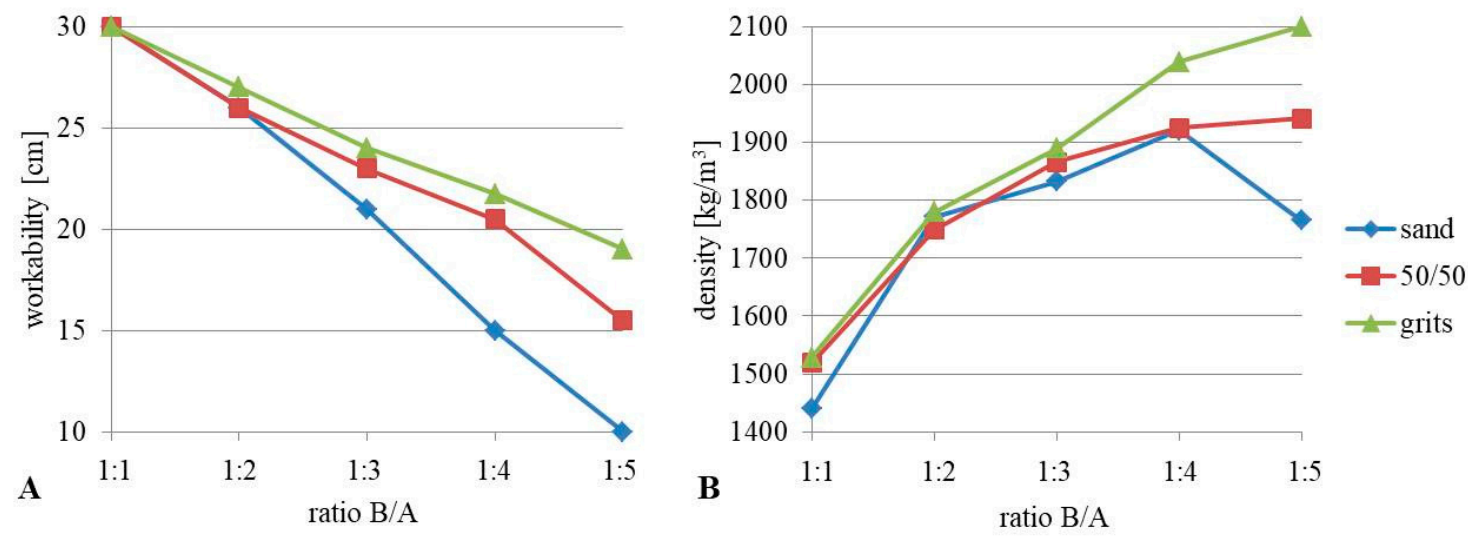

Figure 5. Produced mortars spread values (A) and bulk density (B).

$1: 1$ $1: 2$ $1: 3$

$1: 4$ $1: 5$

sand

(I)

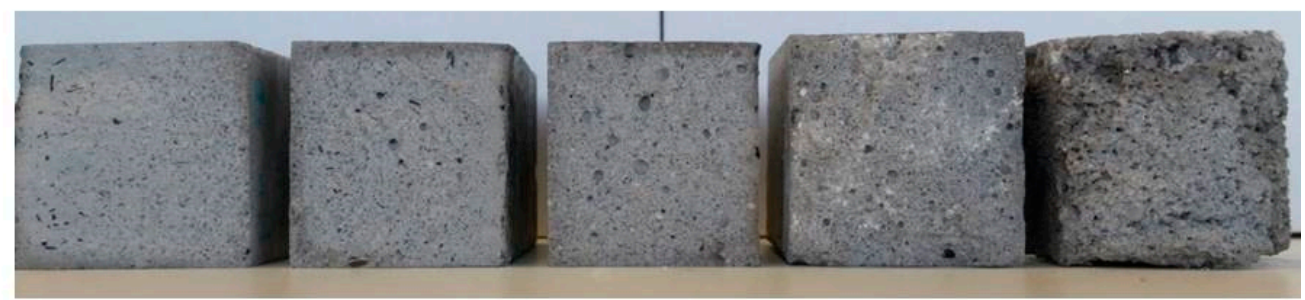

sand + grits

(II)
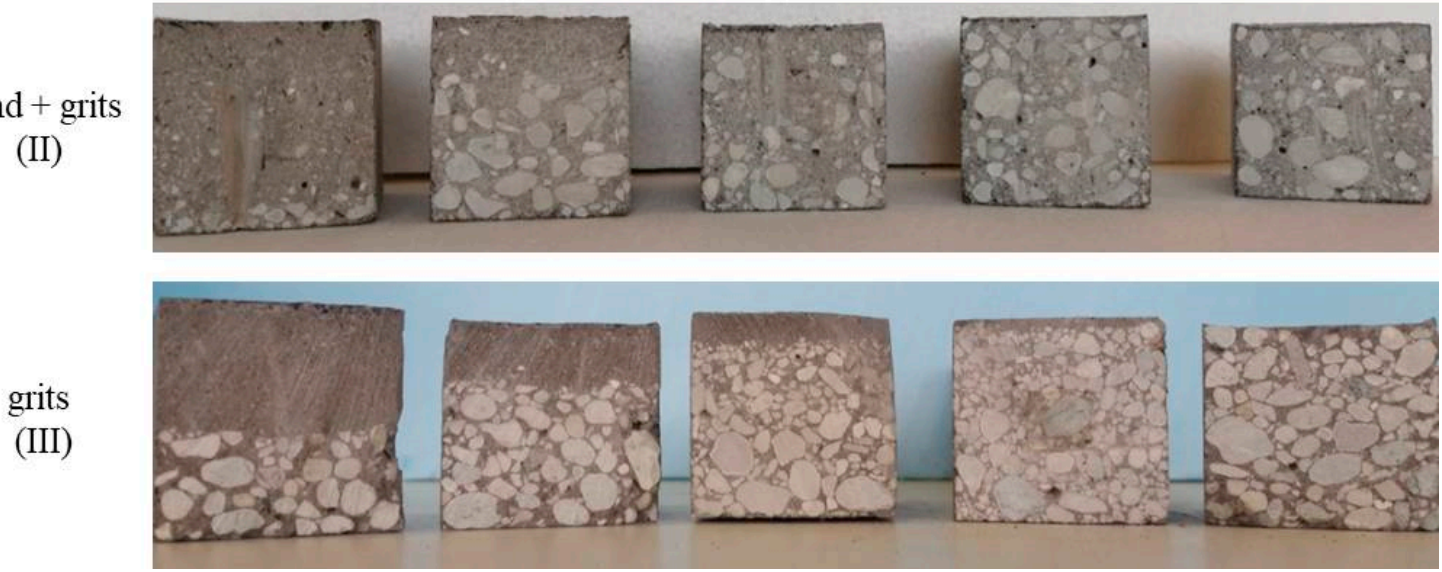

Figure 6. Cross section pictures of the hardened specimens.

In this work, and according to [43], the initial setting time is reported as the moment when the needle penetrated $39 \pm 0.5 \mathrm{~mm}$ of the fresh slurry; the final setting time is when penetration is less than $0.5 \mathrm{~mm}$. The reported values are calculated as the average of three penetrations and are reported in Table 3. The considered mix design had a B/A ratio equal to 1:3, showing an average behaviour between the various formulations.

Table 3. Setting time of the mortars with B/A equal to 1:3.

\begin{tabular}{cccc}
\hline \multirow{2}{*}{ Mortar Family } & \multirow{2}{*}{ Aggregate Nature } & \multicolumn{2}{c}{ Setting Time [min] } \\
\cline { 3 - 4 } & & Initial & Final \\
\hline (I) & sand & 140 & 195 \\
(II) & sand + grits & 145 & 205 \\
(III) & grits & 155 & 215 \\
\hline
\end{tabular}


It can be observed that increasing the slurry fluidity (cf. Figure 5A) delays both the initial and the final setting times. This is a direct consequence of the available free water that makes the pastes more fluid, along with the nature of the aggregate, and accordingly this influences the overall setting time (at the considered curing conditions). In any case, it should be noted that the difference between the three analysed formulations is not considerable and does not negate the applicability of the mortars in construction.

Figures 6 and 7 show the cross sections of the hardened specimens and the SEM images of the three mortars (ratio 1:3), respectively. For each section, the percentage area occupied by the aggregates was calculated as an indicator of the segregation tendency. For all the specimens, increasing the aggregate amount leads to a more homogeneous and compact slurry. Particularly evident is the issue related to workability, especially for the aforementioned formulation n. 5 (family (I), 1:5 B/A 100 wt.\% sand) where large voids were observed. In general, segregation in family (I) was quite irrelevant with, in the worst case, $80 \%$ of the area fully occupied by sand (1:1 B/A). In any case, minor quantities of sand particles were still distributed in the remaining section, resulting in sufficient matrix homogeneity. In family (III), the grit grains, being heavier and coarser than the binder (highly fluid) tend to separate and sink to the bottom. Segregation is particularly evident for the 1:1 and 1:2 formulations where $43 \%$ and $70 \%$, respectively, of the cross area is occupied by the aggregate. This is still visible in the 1:3 sample. A direct disadvantage of segregation is the section choking and the consequent reduction in mechanical strength. Consequently, a specimen behaves as if it is formed by two different parts, weakly bonded together. Possible loads in the same direction of that plane will cause a complete separation with a consequent structural failure. In any case, the segregation phenomenon can be avoided by adding fillers (water reducing chemicals). Family (II), whose slurry fluidity showed intermediate values presents a segregation phenomenon similar to family (I). A more homogeneous distribution would surely increase the general material performance.

As will be fully discussed in the next Section 3.2.2. Mechanical Performance, the high segregation of the aggregates, as in the mortar of family (III), ratio 1:1, or the presence of voids (low homogeneity and compactness), as in the mortar of family (I), ratio 1:5, are directly related to the weakness of the material. On the contrary, a more homogeneous and compact matrix results in higher mechanical performance. This is also observable at the microscale (Figure 7) where mortars of families I (sand) and II (sand + grits) show a more homogeneous matrix. Moreover, the addition of sand (constituted by very thin particle size, cf. Figure 2) contributes to compacting the material matrix, whose binder micrograph is presented in [40]. Analogously to what is observed at the macroscale, the presence of the grit grains, when immersed in the binder paste, generates discontinuities and microcracks that contribute to lowering the overall mechanical resistance.
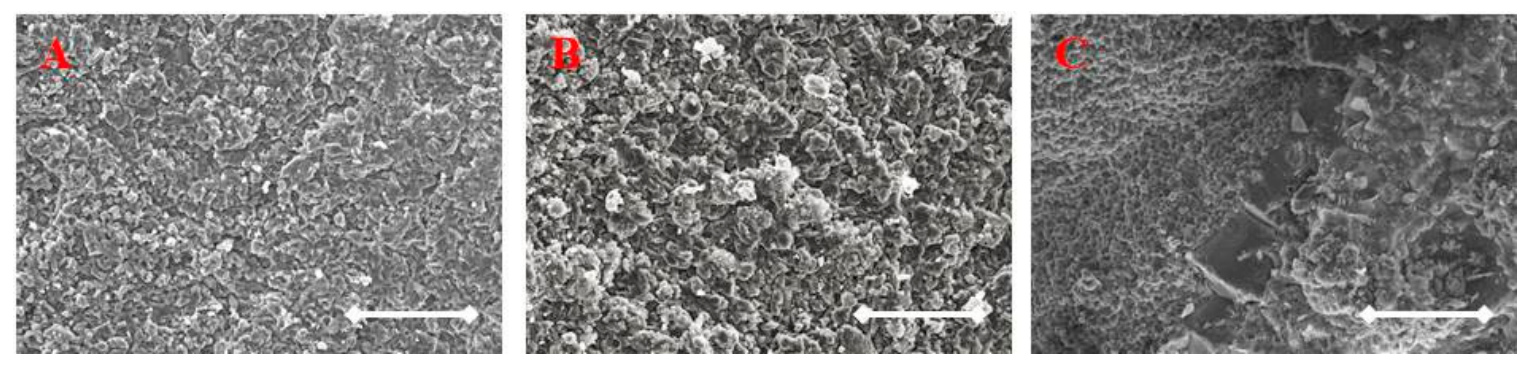

Figure 7. SEM images $(600 \mathrm{X}$, scale bar $=50 \mu \mathrm{m})$ of the three mortars (ratio B/A 1:3): (A) sand; $(\mathbf{B})$ sand + grits; (C) grits.

Analogously, the values for water absorption by immersion and the capillary coefficients are strictly dependent on the aggregate amount and nature, as shown in Figure 8. More particularly, the water sorptivity, both by immersion and capillary action, tends to decrease with an increase in the amount of the aggregates. As grits hardly absorb water, the specimens' overall sorptivity is only due to the action of the binder. Thus, by increasing the amount of aggregate, the quantity of the 
binder diminishes, and consequently, the overall sorptivity. As for density, it can be observed that the GP-mortar of family (I) 1:5 B/A shows a higher sorptivity, contrary to the general trend. That is due to the too pasty slurry (lack of workability) that generates voids. Mortars of family (II) generally show a lower water sorptivity by immersion due to the broader, and more uniform, aggregate particle size distribution. Indeed, such mixed aggregate tends to occupy all the voids preventing the absorption of water. The coefficient of capillary shows an intermediate behaviour.
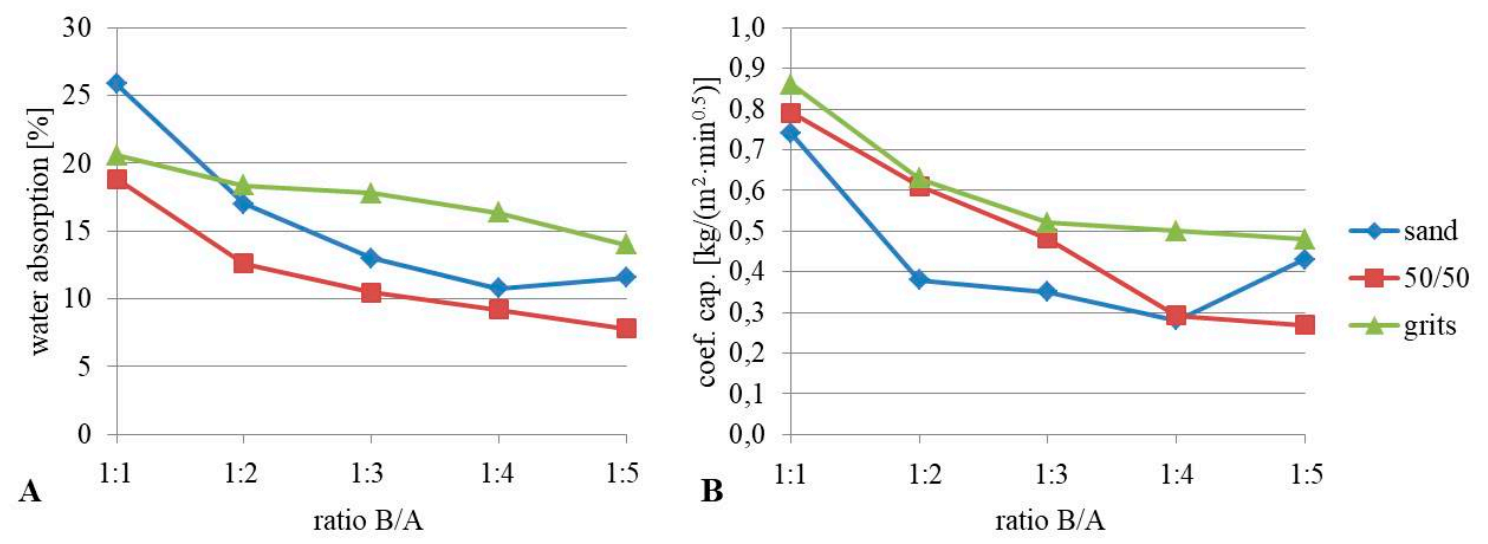

Figure 8. Mortar's water absorption by immersion (A) and coefficient of capillary (B).

\subsubsection{Mechanical Performance}

The mechanical performance of the specimens was assessed at 28 days of curing. Tests were performed in order to avoid any possible section splitting (due to aggregates segregation), so the load was applied perpendicularly to the segregation plane. Figure 9A shows the produced GP-mortars UCS; Figure 9B the axial strains; Figure 9C the stress-strain curves for the 1:3 B/A GP-mortars (representing an intermediate formulation) for the three different families. The binder curve is shown for comparison purposes. Figure 9D shows the stress-strain curves of family (III), grits only.

Most of the formulated GP-mortars showed lower UCS values than that of the pure binder $(22.15 \pm 1.22 \mathrm{MPa})$. As in OPC-based concrete, the binder is the reactive component and the main contributor to the chemical hardening. However, physical parameters such as the material compactness degree, the density, and the ease of workability also affect the mechanical strength.

GP-mortars using sand only (family (I)) show an increasing UCS until 1:3 B/A, which represents the best balance between the two components. For this formulation, the calculated mean UCS was $22.01 \pm 0.03 \mathrm{MPa}$. Then, the UCS starts to decrease due to the decreasing workability of the paste, which, as for the other parameters, negatively influences the overall performance. Simultaneously, by increasing the aggregate amount, the axial strain tends to increase from $\sim 1.7 \%$ to $\sim 2.2 \%$. This behaviour is opposite to that of the grits-based mortars. Moreover, sand makes the material more brittle, lowering the point of shortening at rupture in comparison to the other two families (Figure 9C).

In mortars of family (III), where only grits were used, the observed segregation, which is more evident for formulations containing lower amounts, certainly explains their lower strength. Therefore, an increase in the uniformity of the matrix, subsequent to an increase in the B/A ratio, results in higher UCS. Furthermore, the grits round shape reduces the friction with the paste, contributing to lowering the overall UCS. The maximum measured UCS value was $18.89 \pm 1.26 \mathrm{MPa}$ for the mortar with 1:5 B/A ratio. This family was also the most deformable (Figure 9B) due to a higher shift of grit grains through the paste, caused by their geometry. The mechanical performance is closer to that of the binder (Figure 9C) as the binder occupies a larger volume (in contrast to mortars with sand). Axial strain generally tends to decrease the B/A ratio making the material more brittle (Figure 9D). This can be explained by the increasing compaction of the paste during the loading.

Mortars of family (II), using both grits and sand, show the best UCS values. This is explainable by an optimal paste compaction, mainly due to the broader particle size distribution of the whole 
aggregate. Indeed, sand (finer than grits) tends to fill in the paste voids and helps the dispersion of the heavier grit grains, also preventing them from sinking. Consequently, the phenomenon of segregation is strongly reduced. For all of the compositions, the measured UCS was higher with a generally positive trend when there was an increase in the B/A ratio. At the same time, the mortars become more brittle and show a decrease in the axial strain. Generally speaking, the mechanical performance is more similar to that of family (I) (using sand)with a relatively acceptable deformation along with a higher UCS.

According to EN 998-2, Table 4 reports the classes of resistance of the novel GP-mortars, along with the mean UCS. The main achievement is that all of the produced GP-mortars showed a UCS $\geq$ $10 \mathrm{MPa}$ at 28 days of curing. Thereby, according to the mentioned standards, the novel materials are suitable for masonry applications in construction.
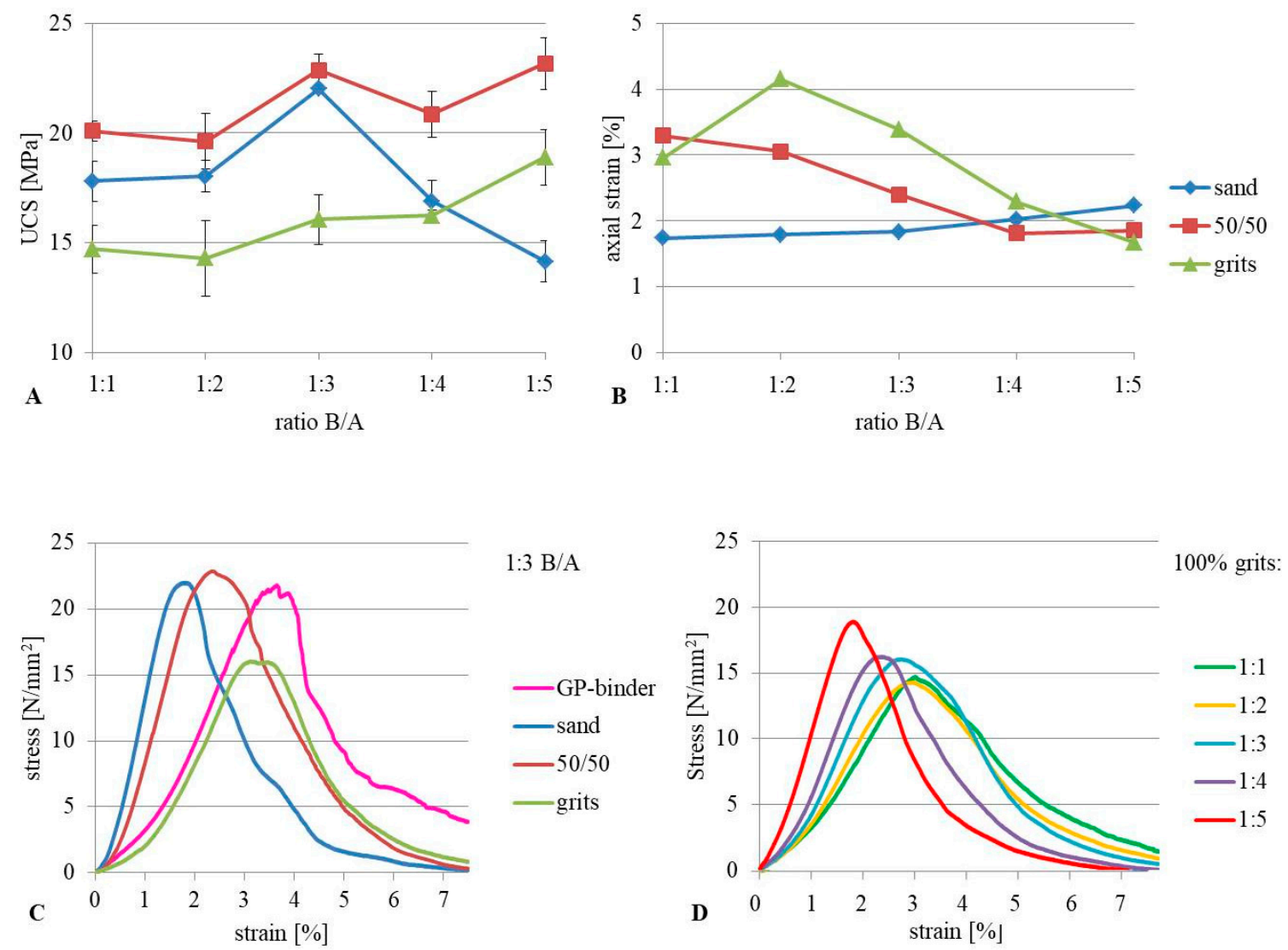

Figure 9. Tested GP-mortars' UCS (A); axial strain (B); stress-strain curves, a comparison between the three mortars with 1:3 B/A (here the binder curve is shown for comparison purposes) (C); curves of the five mortars formulated with grits only (D). 
Table 4. Estimated classes of resistance (EN 998-2).

\begin{tabular}{cccccc}
\hline Mortar Family & $\begin{array}{c}\text { Specimen } \\
\text { N. }\end{array}$ & $\begin{array}{c}\text { B/A } \\
\text { Ratio }\end{array}$ & $\begin{array}{c}\text { Aggregate } \\
\text { Nature }\end{array}$ & $\begin{array}{c}\text { UCS } \\
{[\mathbf{M P a}]}\end{array}$ & $\begin{array}{c}\text { Class of } \\
\text { Resistance }\end{array}$ \\
\hline & 1 & $1: 1$ & & $17.81 \pm 0.91$ & M15 \\
(I) & 2 & $1: 2$ & & $18.03 \pm 0.71$ & M15 \\
& 3 & $1: 3$ & sand & $22.01 \pm 0.03$ & M20 \\
& 4 & $1: 4$ & & $16.88 \pm 0.95$ & M15 \\
& 5 & $1: 5$ & & $14.14 \pm 0.93$ & M10 \\
\hline & 6 & $1: 1$ & & $20.09 \pm 0.46$ & M20 \\
(II) & 7 & $1: 2$ & & $19.62 \pm 1.28$ & M15 \\
& 8 & $1: 3$ & sand + grits & $22.86 \pm 0.72$ & M20 \\
& 1 & $1: 4$ & & $20.85 \pm 1.04$ & M20 \\
& 10 & $1: 5$ & & $23.17 \pm 1.17$ & M20 \\
\hline & 11 & $1: 1$ & & $14.71 \pm 1.09$ & M10 \\
(III) & 12 & $1: 2$ & & $14.29 \pm 1.72$ & M10 \\
& 13 & $1: 3$ & grits & $16.05 \pm 1.13$ & M15 \\
& 14 & $1: 4$ & & $16.24 \pm 0.24$ & M15 \\
& 15 & $1: 5$ & & $18.89 \pm 1.26$ & M15 \\
\hline
\end{tabular}

\section{Conclusions}

This experimental research evaluated the possibility of producing novel sustainable GP-mortars exploiting wastes derived from the Portuguese Kraft pulp-paper industry. BFA was used as an alumino-silicate source to partially replace the MK; grits were used as aggregate. Waste reuse contributes to saving (natural) raw materials and reducing their disposal in landfill, consequently improving the material's sustainability. In order to minimize the phenomenon of segregation, and consequently improve the engineering properties, natural siliceous sand was also mixed to broaden the aggregate particle size distribution.

Contrary to what is commonly done in GP-technology, the performed processes of manufacture and cure occurred at ambient conditions, thus avoiding any external source of energy. Indeed, a quite high temperature $\left(40-80^{\circ} \mathrm{C}\right.$ for about $\left.24 \mathrm{~h}\right)$ is generally reported in order to quickly activate and accelerate the reactions of geopolymerisation, and consequently gain early high resistance. Such common procedures consume a high amount of energy (i.e., electricity) and produce pollution (i.e., $\mathrm{CO}_{2}$ emissions). The procedure followed in this paper avoids such undesirable elements by performing the whole manufacture at ambient conditions. This contributes to enhancing the sustainability of the novel materials, lowering the overall environmental footprint. Moreover, the simple and low-cost processing steps contribute to simplifying the manufacturing process, reducing de facto the overall process footprint.

Experiments revealed that grits can be efficiently reused as aggregates in GP-mortars intended for application in construction. All the tested formulations belong at least to class M10 (UCS $\geq 10 \mathrm{MPa}$ ), which is the minimum requirement for masonry applications. Experiments showed that for the tested conditions, the suboptimal B/A ratio should be higher than 1:3 to avoid segregation. The addition of sand drastically reduces this phenomenon, leading to a more uniform paste with improved properties.

The best formulation, in terms of mechanical resistance, comprises 1 part of binder vs. 5 parts of aggregate, for both grits and grits + sand. The respective UCSs were $18.89 \pm 1.26 \mathrm{MPa}$ and $23.17 \pm 1.17 \mathrm{MPa}$, respectively. Conversely, their consistency was quite pasty (insufficient workability). Nevertheless, these parameters may be easily adjusted by using specific chemicals. In line with analogous construction materials, the $\mathrm{B} / \mathrm{A}$ ratio influenced the characteristics of the tested material. By increasing the aggregate amount (decreasing the B/A ratio) these novel GP-mortars tended to show a more uniform paste with higher UCS and lower stiffness. In addition, the water sorptivity, either by immersion and capillary action, tended to decrease in line with the binder reduction, which is mainly responsible for absorption. 
From the conducted experiments, it is concluded that all the produced GP-mortars are suitable for use in construction such as masonry/structural applications. Moreover, the reuse of grits as a novel aggregate is highly recommended rather than its disposal of in landfill.

Further studies will investigate the employment of chemicals to adjust the slurry workability and limit/avoid the phenomenon of segregation, as well as the influence of waste-based aggregates on the setting time, shrinkage, and on the main engineering properties. Finally, tests on durability will be set to investigate the performance of the novel materials under prolonged harsh situations.

Author Contributions: The experimental plan was designed by M.S. The specimens were produced by M.S. and L.S., who made the flow table test. The mortars full characterisation was performed by M.S., D.M.T. carried out the mineralogical analysis. J.A.L., M.P.S. and G.L.S. were in charge of the scientific coordination and funding (see fundings). All the authors were involved in the manuscript preparation.

Funding: This work is financed by Portugal 2020 through the European Regional Development Fund (ERDF) in the frame of the Operational Competitiveness and Internationalization Programme (POCI) in the scope of the project PROTEUS-POCI-01-0247-FEDER-017729 and in the scope of the project CICECO-Aveiro Institute of Materials, FCT Ref. UID/CTM/50011/2019, financed by national funds through the FCT/MCTES. David M. Tobaldi is grateful to Portuguese national funds (OE), through FCT, I.P., in the scope of the framework contract foreseen in number 4, 5 and 6 of article 23, of the Decree-Law 57/2016, of August 29, changed by Law 57/2017, of July 19.

Acknowledgments: Cristina Sequeira (Department of Geoscience, University of Aveiro) is acknowledged for the XRF analysis. Saint-Gobain Weber Portugal (Aveiro) is acknowledged for providing the sand.

Conflicts of Interest: The authors declare no conflict of interest.

\section{References}

1. Directive 2008/98/EC of the European Parliament and of the Council of 19 November 2008 on Waste. Available online: https://eur-lex.europa.eu/legal-content/EN/TXT/?uri=celex\%3A32008L0098 (accessed on 25 June 2019).

2. Kumar, S.A. Entrepreneurship Development; New Age Int.: New Delhi, India, 2008.

3. Martin Hirschnitz-Garbers, A.R.T.; Gradmann, A.; Srebotnjak, T. Key drivers for unsustainable resource use-categories, effects and policy pointers. J. Clean. Prod. 2016, 132, 13-31. [CrossRef]

4. Qian, C. Sustainable Construction Methods and Processes. In Encyclopedia of Sustainable Technologies, Reference Module in Earth Systems and Environmental Sciences; Abraham, M.A., Ed.; Elsevier: Amsterdam, The Netherlands, 2017; pp. 321-329.

5. Kylili, A.; Fokaides, P.A. Policy trends for the sustainability assessment of construction materials: A review. Sustain. Cities Soc. 2017, 35, 280-288. [CrossRef]

6. Mehta, P.K. Sustainable cements and concrete for the climate change era-A review. In Proceedings of the Second International Conference on Sustainable Construction Materials and Technologies, Ancona, Italy, 28-30 June 2010; Zachar, J., Claisse, P., Naik, T.R., Ganjian, E., Eds.; Università Politecnica Delle Marche: Ancona, Italy, 2010; pp. 1-10.

7. Schneider, M.; Romer, M.; Tschudin, M.; Bolio, H. Sustainable cement production-present and future. Cem. Concr. Res. 2011, 41, 642-650. [CrossRef]

8. Van Oss, H.G. Background Facts and Issues Concerning Cement and Cement Data. U.S. Department of the Interior and U.S Geological Survey, 2005. Available online: https://pubs.usgs.gov/of/2005/1152/2005-1152.pdf (accessed on 25 June 2019).

9. Singh, B.; Ishwarya, G.; Gupta, M.; Bhattacharyya, S.K. Geopolymer concrete: A review of some recent developments. Constr. Build. Mater. 2015, 85, 78-90. [CrossRef]

10. Patel, Y.J.; Shah, N. Development of self-compacting geopolymer concrete as a sustainable construction material. Sustain. Environ. Res. 2018, 28, 412-421. [CrossRef]

11. Hassan, A.; Arif, M.; Shariq, M. Use of geopolymer concrete for a cleaner and sustainable environment-A review of mechanical properties and microstructure. J. Clean. Prod. 2019, 223, 704-728. [CrossRef]

12. Ma, C.K. Structural and material performance of geopolymer concrete: A review. Constr. Build. Mater. 2018, 186, 90-102. [CrossRef]

13. Connie, N.G.; Johnson Alengaram, U.; Wong, L.S.; Mo, K.H.; Ramesh, S. A review on microstructural study and compressive strength of geopolymer mortar, paste and concrete. Constr. Build. Mater. 2018, 186, 550-576. 
14. Zhang, P.; Zheng, Y.; Wang, K.; Zhang, J. A review on properties of fresh and hardened geopolymer mortars. Compos. Part B Eng. 2018, 152, 79-95. [CrossRef]

15. Pacheco-Torgal, F.; Abdollahnejad, Z.; Camões, A.F.; Jamshidi, M.; Ding, Y. Durability of alkali-activated binders: A clear advantage over Portland cement or an unproven issue? Constr. Build. Mater. 2012, 30, 400-405. [CrossRef]

16. Turner, K.; Collins, F.G. Carbon dioxide equivalent $\left(\mathrm{CO}_{2}-\mathrm{e}\right)$ emissions: A comparison between geopolymer and OPC cement concrete. Constr. Build. Mater. 2013, 43, 125-130. [CrossRef]

17. Sandanayake, M.; Gunasekara, C.; Law, D.; Zhang, G.; Setunge, S. Greenhouse gas emissions of different fly ash based geopolymer concretes in building construction. J. Clean. Prod. 2018, 204, 399-408. [CrossRef]

18. Davidovits, J. Synthesis of New High Temperature Geo-Polymers for Reinforced Plastics/Composites; Society of Plastic Engineers, Brookfield Center: New York, NY, USA, 1979; Volume 79, pp. 151-154.

19. Davidovits, J. Geopolymer Chemistry and Applications; Institut Géopolymère: Saint-Quentin, France, 2008.

20. Duxson, P.; Fernandez-Jimenez, A.; Provis, J.L.; Lukey, G.C.; Palomo, A.; van Deventer, J.S.J. Geopolymer technology: The current state of the art. J. Mater. Sci. 2007, 42, 2917-2933. [CrossRef]

21. Komnitsas, K.; Zaharaki, D. Geopolymerisation: A review and prospects for the minerals industry. Miner. Eng. 2007, 20, 1261-1277. [CrossRef]

22. Grace, T.M.; Leopold, B.; Malcolm, E.W. Alkaline Pulping. In Pulp and Paper Manufacture; Kocurek, M.J., Stevens, F., Eds.; Joint Textbook Committee of the Paper Industry of the United States and Canada: Atlanta, GA, USA, 1991; Volume 5.

23. Sixta, H. Handbook of Pulp; Wiley-VHC: Weinheim, Germany, 2006.

24. Ek, M.; Gellerstedt, G.; Henriksson, G. Pulping Chemistry and Technology; de Gruyter: Berlin, Germany, 2009.

25. European Union. Council Directive 1999/31/EC of 26 April 1999 on the Landfill of Waste. Available online: https://eur-lex.europa.eu/legal-content/EN/TXT/?uri=celex\%3A31999L0031 (accessed on 25 June 2019).

26. Naik, T.R. Tests of Wood Ash as a Potential Source for Construction Materials; Report, No. CBU-1999-09; UWM Center for by-Products Utilization, University of Wisconsin-Milwaukee: Milwaukee, WI, USA, 1999.

27. Wang, S.; Baxter, L. Comprehensive study of biomass fly ash in concrete: Strength, microscopy, kinetics and durability. Fuel Process Technol. 2007, 88, 1165-1170. [CrossRef]

28. Rajamma, R.; Ball, R.J.; Tarelho, L.A.; Allen, G.C.; Labrincha, J.A.; Ferreira, V.M. Characterisation and use of biomass fly ash in cement-based materials. J. Hazard. Mater. 2009, 172, 1049-1060. [CrossRef] [PubMed]

29. Hardjito, D.; Wallah, S.E.; Sumajouw, D.M.J.; Rangan, B.V. On the development of fly ash based geopolymer concrete. ACI Mater. J. 2004, 101, 467-472.

30. Rajamma, R.; Labrincha, J.A.; Ferreira, V.M. Alkali activation of biomass fly ash-metakaolin blends. Fuel 2012, 98, 265-271. [CrossRef]

31. Yliniemi, J.; Paiva, H.; Ferreira, V.M.; Tiainen, O.Y.; Illikainen, M. Development and incorporation of lightweight waste-based geopolymer aggregates in mortar and concrete. Constr. Build. Mater. 2017, 131, 784-792. [CrossRef]

32. Panda, B.; Tan, M.J. Experimental study on mix proportion and fresh properties of fly ash based geopolymer for 3D concrete printing. Ceram. Int. 2018, 44, 10258-10265. [CrossRef]

33. Panda, B.; Paul, S.C.; Hui, L.J.; Tay, Y.W.D.; Tan, M.J. Additive manufacturing of geopolymer for sustainable built environment. J. Clean. Prod. 2017, 167, 281-288. [CrossRef]

34. Novais, R.M.; Ascensão, G.; Tobaldi, D.M.; Seabra, M.P.; Labrincha, J.A. Biomass fly ash geopolymer monoliths for effective methylene blue removal from wastewaters. J. Clean. Prod. 2018, 171, 783-794. [CrossRef]

35. Novais, R.M.; Carvalheiras, J.; Tobaldi, D.M.; Seabra, M.P.; Pullar, R.C.; Labrincha, J.A. Synthesis of porous biomass fly ash-based geopolymer spheres for efficient removal of methylene blue from wastewaters. J. Clean. Prod. 2019, 207, 350-362. [CrossRef]

36. Ikhmayies, S.; Li, B.; Carpenter, J.S.; Li, J.; Hwang, J.-Y.; Monteiro, S.N.; Firrao, D.; Zhang, M.; Peng, Z.; Escobedo-Diaz, J.P.; et al. Characterization of Minerals, Metals, and Materials; Springer: Cham, Switzerland, 2017.

37. Siqueira, F.B.; Holanda, J.N.F. Reuse of grits waste for the production of soil-cement bricks. J. Environ. Manag. 2013, 131, 1-6. [CrossRef] [PubMed]

38. Siqueira, F.B.; Holanda, J.N.F. Efeito da incorporação de resíduo grits sobre o comportamento de densificação de tijolo solo-cimento. Cerâmica 2015, 61, 414-419. [CrossRef] 
39. Saeli, M.; Novais, R.M.; Seabra, M.P.; Labrincha, J.A. Mix design and mechanical performance of geopolymer binder for sustainable construction and building material. IOP Conf. Ser. Mater. Sci. Eng. 2017, 264, 012002. [CrossRef]

40. Saeli, M.; Tobaldi, D.M.; Seabra, M.P.; Labrincha, J.A. Mix design and mechanical performance of geopolymeric binders and mortars using biomass fly ash and alkaline effluent from paper-pulp industry. J. Clean. Prod. 2019, 208, 1188-1197. [CrossRef]

41. Saeli, M.; Novais, R.M.; Seabra, M.P.; Labrincha, J.A. Green geopolymeric concrete using grits for applications in construction. Mater. Lett. 2018, 233, 94-97. [CrossRef]

42. Chudley, R.; Greeno, R. Building Construction Handbook; Routledge: Abingdon, UK, 2016.

43. Sleiman, H.; Perrot, A.; Amziane, S. A new look at the measurement of cementitious paste setting by Vicat test. Cem. Concr. Res. 2010, 40, 681-686. [CrossRef]

(C) 2019 by the authors. Licensee MDPI, Basel, Switzerland. This article is an open access article distributed under the terms and conditions of the Creative Commons Attribution (CC BY) license (http://creativecommons.org/licenses/by/4.0/). 